\title{
Addition of a chiral non-racemic silyloxypyrrole to an activated 1,4-benzoquinone
}

\author{
Rosliana Halim, Margaret A. Brimble,* and Paul D.Woodgate \\ Department of Chemistry, University of Auckland, Private Bag 92019, Auckland, New Zealand. \\ E-mail: m.brimble@auckland.ac.nz
}

\begin{abstract}
The uncatalyzed addition of enantiopure silyloxypyrrole 3 to 2-carbomethoxy-1,4-benzoquinone $\mathbf{4}$ in acetonitrile at ambient temperature afforded pyrrolidinonobenzofuran adducts $\mathbf{5}$ and $\mathbf{6}$ in low yield. The two adducts were separated by flash chromatography and the structures of these diastereomers were determined using high field NMR spectroscopy combined with molecular modelling studies. The work reported herein provides the first example of the annulation of a 1,4-benzoquinone with a chiral non-racemic silyloxypyrrole.
\end{abstract}

Keywords: Silyloxypyrroles, quinone, annulation, pyrrolidinonobenzofuran, aza-analogues of pyranonaphthoquinones

\section{Introduction}

We have previously reported the uncatalyzed addition of 2-trimethylsilyloxyfuran to 1,4benzoquinones and 1,4-naphthoquinones that bear an electron withdrawing group at $\mathrm{C}$-2, as an efficient entry to the respective furobenzofuran and furonaphthofuran annulation products. ${ }^{1}$ In the case of the furonaphthofuran adducts these products then underwent smooth oxidative rearrangement providing the pyranonaphthoquinone skeleton present in the isochromanquinone family of antibiotics (Scheme 1). ${ }^{2}$ As part of an on-going programme directed towards effecting an asymmetric variant of this furofuran annulation of an activated quinone we initiated an investigation of the asymmetric addition of the related homochiral silyloxypyrrole 3 to benzoquinone 4 as a method to prepare chiral non-racemic pyrrolidinonobenzofurans, which have potential use for the synthesis of aza-analogues of the naturally occurring pyranonaphthoquinone antibiotics. 


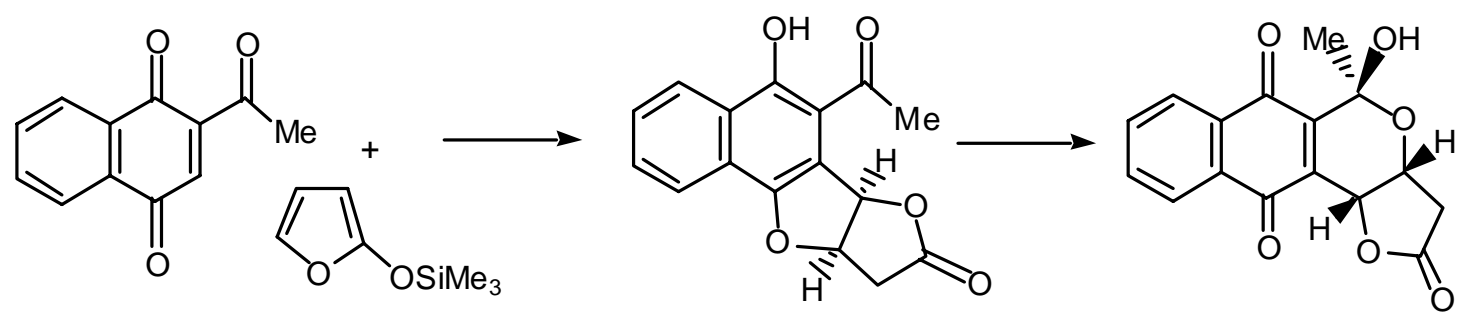

\section{Scheme 1}

The asymmetric Mukaiyama addition of a chiral non-racemic silyloxypyrrole to achiral aldehydes $^{3}$ has been reported providing a method for the diastereoselective synthesis of polyhydroxylated pyrrolidines ${ }^{4}$ and aza-analogues of the acetogenin muricatacin. ${ }^{5}$ A chiral nonracemic silyloxypyrrole has also been condensed with aromatic imines ${ }^{6}$ and achiral silyloxypyrroles have been condensed with $\mathrm{N}$-acyl iminium ions. ${ }^{7}$ Attempts to effect the annulation of an activated 1,4-benzoquinone with a chiral non-racemic silyloxypyrrole have not been reported to date and are the subject of the work reported herein.

\section{Results and Discussion}

Chiral non-racemic silyloxypyrrole 3 was readily prepared (Scheme 2) from (R)-(-)-2phenylglycinol, which in turn was readily obtained by reduction of $(R)-(-)$-2-phenylglycine with lithium borohydride and chlorotrimethylsilane ${ }^{8,9}(R)-(-)-2-$ Phenylglycinol was then reacted with 2,5-dimethoxy-2,5-dihydrofuran in water at $\mathrm{pH} 1$ to afford dihydropyrrol-2-one 1 . The optimal reaction time was $3 \mathrm{~h}$; if longer times were used, the yield of the desired product decreased. Before carrying out a standard aqueous work-up, solid sodium bicarbonate was added to the reaction mixture. This neutralization step was critical in obtaining the maximum yield of product. The literature procedure ${ }^{10}$ reported a $75 \%$ yield for this reaction. However, the maximum yield of a single isomer product in the present work was 56\%. Purification by flash chromatography was essential before carrying out the next step.

Standard acetylation of dihydropyrrol-2-one $\mathbf{1}$ by reaction with acetic anhydride in dichloromethane using 4-(dimethylamino)pyridine as catalyst afforded acetate 2 in $70 \%$ yield after flash chromatography. Finally, silylation of lactam 2 was carried out following a method described by Royer et al. ${ }^{4}$ for the analogous benzoate derivative. Acetate 2 was reacted with tertbutyldimethylsilyl trifluoromethanesulfonate and triethylamine in dichloromethane, affording silyloxypyrrole 3 in 69\% yield after purification by chromatography on alumina.

Silyloxypyrrole $\mathbf{3}$ was sensitive to acid and storage of the product was problematic in that after one to two days in the freezer it decomposed to give lactam 2, despite the use of basewashed glassware. It therefore proved necessary to prepare silyloxypyrrole $\mathbf{3}$ freshly and use it directly in the next reaction. 


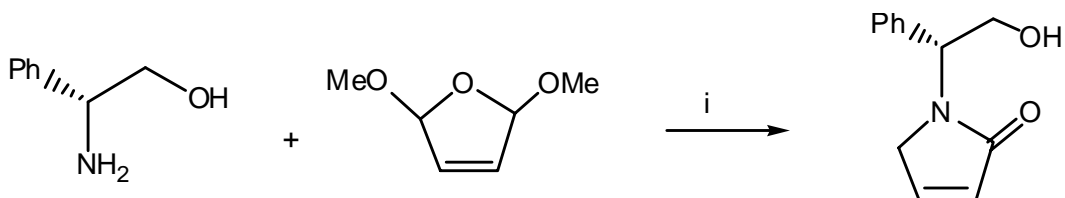

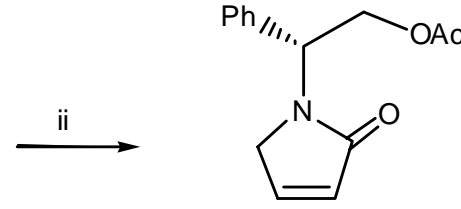

2

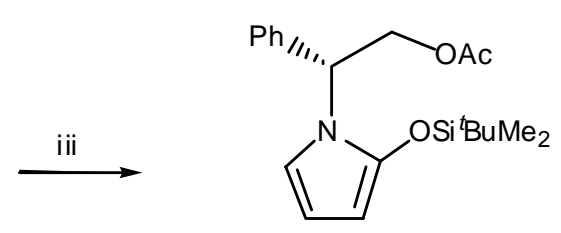

3

Reagents and Conditions: i. $\mathrm{H}_{2} \mathrm{O}, \mathrm{HCl}, 3 \mathrm{~h}, 56 \%$; ii. $\left(\mathrm{CH}_{3} \mathrm{CO}\right)_{2} \mathrm{O}, \mathrm{Et}_{3} \mathrm{~N}, \mathrm{DMAP}, \mathrm{CH}_{2} \mathrm{Cl}_{2}, 70 \%$; iii. $\mathrm{Me}_{2}{ }^{\mathrm{t}} \mathrm{BuSiOTf}, \mathrm{CH}_{2} \mathrm{Cl}_{2}, \mathrm{Et}_{3} \mathrm{~N}, 1 \mathrm{~h}, 69 \%$.

\section{Scheme 2}

Reaction of silyloxypyrrole 3 with 2-carbomethoxy-1,4-benzoquinone 4 (1 equivalent) in acetonitrile at room temperature for $21 \mathrm{~h}$, followed by the addition of a catalytic quantity of pyridinium p-toluenesulfonate, afforded pyrrolidinonobenzofurans 5 and $\mathbf{6}$ in 12\% and 3\% yield respectively after careful purification by PLC on silica gel (Scheme 3). The low isolated yields were attributed to the decomposition of the products on silica gel. 2,5-Dihydroxybenzoate 7 and lactam 2 were also obtained as major by-products from this reaction. 2,5-Dihydroxybenzoate 7 results from reduction of the starting benzoquinone $\mathbf{4}$ and lactam 2 results from hydrolysis of the starting silyloxypyrrole $\mathbf{3}$. Increasing the ratio of silyloxypyrrole to quinone $\mathbf{4}$ did not improve the yield of the desired adducts 5 and 6. Disappointingly, extensive investigation of alternative solvents, mildly acidic additives, fluoride sources and several Lewis acid catalysts did not improve the outcome of this reaction.

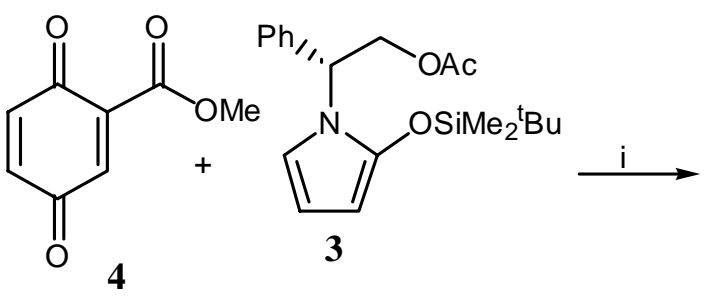

Reagents and Conditions: i. $\mathrm{CH}_{3} \mathrm{CN}$, room temp., 21 h, 5 (3\%), $6(12 \%)$.

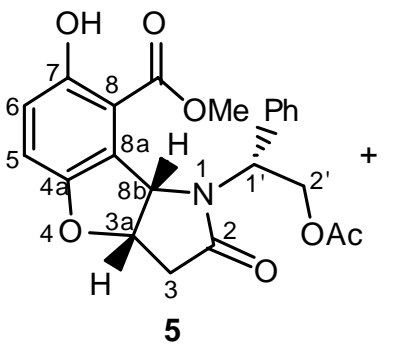<smiles>COC(=O)c1c(O)ccc2c1[C@@]1(C)[C@@H](CC(=O)N1[C@H](COC(C)=O)c1ccccc1)O2</smiles>

6

\section{Scheme 3}

Given the nature of the two by-products observed, namely hydroquinone 7 and lactam 2, it was proposed that the Michael addition reaction did not proceed well in this case. Silyloxypyrrole $\mathbf{3}$ is electron rich containing both a phenylethyl group at $\mathrm{N}-1$ and a silyloxy 
group at C-2. It is therefore proposed that an electron transfer process takes place with donation of electron(s) to benzoquinone 4 leading to formation of hydroquinone $\mathbf{7}$ and lactam $\mathbf{2}$ (Scheme 4).

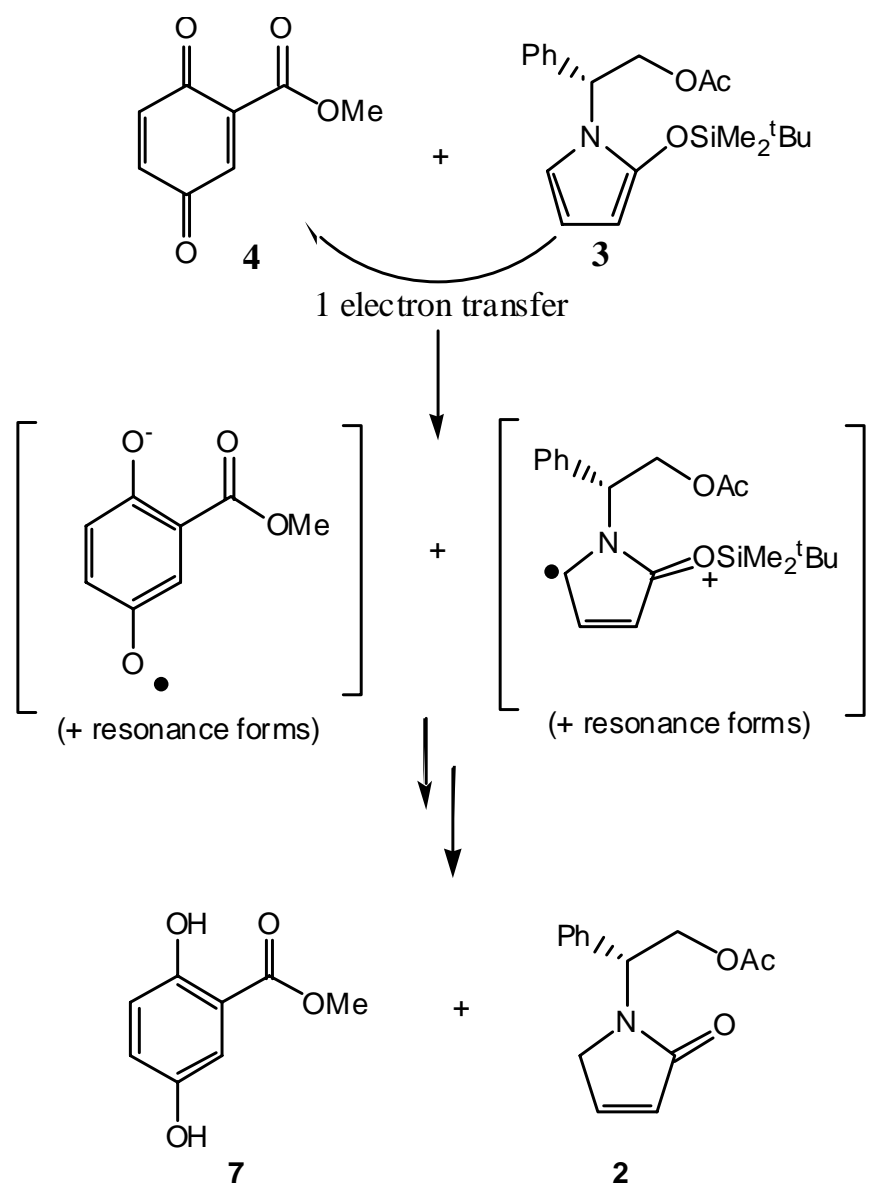

\section{Scheme 4}

In order to avoid the undesired outcomes of electron transfer, it was proposed to execute the reaction in the presence of an oxidant that would re-oxidise any hydroquinone $\mathbf{7}$ that formed to 1,4-benzoquinone 4 so that it could undergo reaction with silyloxypyrrole 3 thereby improving the yield of adducts 5 and $\mathbf{6}$. With this idea in mind, a reaction was carried out using a 1:1 ratio of silyloxypyrrole $\mathbf{3}$ to benzoquinone $\mathbf{4}$ in acetonitrile as solvent with manganese dioxide as the oxidant. However, again only low yields of the desired adducts $\mathbf{5}$ and $\mathbf{6}$ were obtained.

The ${ }^{1} \mathrm{H}$ n.m.r. spectrum of the less polar pyrrolidinonobenzofuran diastereomer $\mathbf{6}$ included a characteristic doublet at $\delta_{\mathrm{H}} 5.52$ and a triplet at $\delta_{\mathrm{H}} 5.19$, assigned to the bridgehead protons $\mathrm{H}-8 \mathrm{~b}$ and $\mathrm{H}-3 \mathrm{a}$, respectively. The magnitude of the bridgehead coupling constant $J_{3 \mathrm{a}, 8 \mathrm{~b}}$ was $5.0 \mathrm{~Hz}$, consistent with the cis-fusion of the two-membered rings. The spectrum also exhibited a two proton multiplet at $\delta_{\mathrm{H}} 2.90$ assigned to $\mathrm{H}-3$, this chemical shift being consistent with the loss of the aromatic character from the starting pyrrole 3 . A doublet of doublets at $\delta_{\mathrm{H}} 4.48$ and a triplet 
at $\delta_{\mathrm{H}} 5.00$ were assigned to the diastereotopic protons $\mathrm{H}-2$ 'B and H-2'A respectively, with $J_{\text {gem }}$ $10.9 \mathrm{~Hz}$.

An unexpected observation in the ${ }^{1} \mathrm{H}$ n.m.r. spectrum was the nature of the resonance assigned to $\mathrm{H}-1$ '. At ambient probe temperature, $\mathrm{H}-1$ ' resonated as a broad singlet at $\delta_{\mathrm{H}} 4.70$, not a doublet of doublets as expected. This was thought to be caused by restricted rotation about the $\mathrm{N}-\mathrm{C} 1$ ' bond. In order to establish this, variable temperature spectra were recorded using a heated probe. The temperature was gradually increased to $55^{\circ} \mathrm{C}$ and the spectra were collected at $37^{\circ} \mathrm{C}$, $50^{\circ} \mathrm{C}$, and $55^{\circ} \mathrm{C}$. As the temperature increased, changes in the appearance of the resonance assigned to $\mathrm{H}-1$ ' were observed, and at $55^{\circ} \mathrm{C}$, this resonance emerged as a partially resolved doublet of doublets. The chemical shift for the resonance assigned to $\mathrm{H}-1^{\prime}$ was also confirmed in the COSY spectrum at ambient probe temperature, which showed a correlation between $\mathrm{H}-1^{\prime}\left(\delta_{\mathrm{H}}\right.$ 4.70) and $\mathrm{H}-2 \mathrm{~B}\left(\delta_{\mathrm{H}} 4.48\right)$. In the ${ }^{13} \mathrm{C}$ n.m.r. spectrum, $\mathrm{C}-1$ ' resonated as a broad signal, further suggesting restricted rotation about the $\mathrm{N}-\mathrm{C} 1{ }^{\prime}$ bond. In the HSQC spectrum obtained at ambient probe temperature, $\mathrm{H}-1$ ' did not show any correlation with any carbon. However, as the temperature was raised to $55^{\circ} \mathrm{C}$, a correlation was observed between $\mathrm{H}-1^{\prime}$ at $\delta_{\mathrm{H}} 4.70$ and $\mathrm{C}-1^{\prime}$ at $\delta_{\mathrm{C}} 56.2$.

The ${ }^{1} \mathrm{H}$ n.m.r. spectrum of the more polar diastereomer $\mathbf{5}$ was similar to that of the less polar diastereomer 6. The chemical shift for the bridgehead proton H-3a was unchanged, while H-8b resonated further downfield at $\delta_{\mathrm{H}} 5.62$. H-3a resonated as a multiplet in diastereomer 5 rather than as a triplet in diastereomer $\mathbf{6}$. The magnitude of the bridgehead coupling constant in $\mathbf{5}, J_{3 \mathrm{a}, 8 \mathrm{~b}}$ $5.1 \mathrm{~Hz}$, was also similar to that observed in diastereomer 6. The chemical shift for $\mathrm{H}-3$ was unchanged, but the signal for the methoxy group in the more polar diastereomer $\mathbf{5}$ shifted downfield to $\delta_{\mathrm{H}} 3.98$. One of the H-2' protons shifted downfield to $\delta_{\mathrm{H}} 4.63$ while the chemical shift of the other proton was unchanged. The geminal coupling, $J_{\text {gem }} 11.0 \mathrm{~Hz}$, was similar to that observed for diastereomer $\mathbf{6}$. The resonance assigned to $\mathrm{H}-1$ ' in diastereomer $\mathbf{5}$ was not broad as was observed in the less polar diastereomer 6, resonating as a doublet of doublets $\left(J_{1^{\prime}, 2^{\prime} \mathrm{A}} 8.0 \mathrm{~Hz}\right.$ and $J_{1^{\prime}, 2^{\prime} \mathrm{B}} 6.3 \mathrm{~Hz}$ ) at $\delta_{\mathrm{H}} 4.76$ at ambient probe temperature. The ${ }^{13} \mathrm{C}$ NMR spectrum of the more polar diastereomer $\mathbf{5}$ was very similar to that observed for diastereomer $\mathbf{6}$, all of the signals being shifted slightly downfield.

Assignment of the relative stereochemistry was made by obtaining a NOESY spectrum for each diastereomer, and then comparing these results with molecular modelling studies carried out using PC Spartan Pro. In order to observe a correlation in the NOESY spectra, the two protons involved must be less than $3.5 \AA$ apart. The major difference in the NOESY spectra of 5 and $\mathbf{6}$ was the correlation between one of the bridgehead protons $\mathrm{H}-8 \mathrm{~b}$ to the ortho-hydrogen in the phenyl group and also to H-1'. The less polar diastereomer 6 showed a strong correlation between $\mathrm{H}-8 \mathrm{~b}$ and the phenyl hydrogen and also a weak correlation between $\mathrm{H}-8 \mathrm{~b}$ and $\mathrm{H}-1$ '. The more polar diastereomer 5 showed a strong correlation between $\mathrm{H}-8 \mathrm{~b}$ and $\mathrm{H}-1$ ', but no correlation between $\mathrm{H}-8 \mathrm{~b}$ and the phenyl hydrogen was observed. Thus, in the molecular modelling studies, the main focus was to calculate the distance between $\mathrm{H}-8 \mathrm{~b}$ and the phenyl group at C-1'. 
The computed models of the two diasteromers are shown in Figure 1. The energy of each diastereomer for both models was calculated using molecular mechanics for the lowest energy conformer. In molecular model A the stereochemistry at C-3a and C-8b is $S$. The distance between $\mathrm{H}-8 \mathrm{~b}$ and the closest ortho hydrogen in the phenyl ring is $4.7 \AA$, and the distance between $\mathrm{H}-8 \mathrm{~b}$ and $\mathrm{H}-1^{\prime}$ is $2.6 \AA$. This corresponded to the observation found in the NOESY spectrum of the more polar diastereomer 5, which showed no correlation between $\mathrm{H}-8 \mathrm{~b}$ and a phenyl hydrogen but did show a correlation between $\mathrm{H}-8 \mathrm{~b}$ and $\mathrm{H}-1$ '.

In molecular model $\mathrm{B}$ the stereochemistry at $\mathrm{C}-3 \mathrm{a}$ and $\mathrm{C}-8 \mathrm{~b}$ positions is $R$. In this model, the distance between $\mathrm{H}-8 \mathrm{~b}$ and the closest ortho hydrogen in the phenyl ring was $3.0 \AA$, and the distance between $\mathrm{H}-8 \mathrm{~b}$ and $\mathrm{H}-1$ ' is $2.8 \AA$. This corresponds to the NOESY spectrum observed for the less polar diastereomer 6, which exhibited a strong correlation between $\mathrm{H}-8 \mathrm{~b}$ and a phenyl hydrogen and a weaker correlation between $\mathrm{H}-8 \mathrm{~b}$ and $\mathrm{H}-1$ '.

Thus, from the NOESY spectra and the molecular modelling studies, it was determined that the more polar diastereomer was methyl ( $3 a S, 8 b S, 1 ' R)$-1-(2-acetoxy-1-phenylethyl)-7-hydroxy2-oxo-2,3,3a,8b-tetrahydro-1H-[1]benzofuro[3,2-b]pyrrole-8-carboxylate 5 and the less polar diastereomer was methyl (3aR, 8bR, 1'R)-1-(2-acetoxy-1-phenylethyl)-7-hydroxy-2-oxo2,3,3a,8b-tetrahydro-1H-[1]benzofuro[3,2-b]pyrrole-8-carboxylate $\mathbf{6}$. The energy calculated for the more polar diastereomer 5 was $92.295 \mathrm{~kJ} \mathrm{~mol}^{-1}$ and that for the less polar diastereomer $\mathbf{6}$ was $90.350 \mathrm{~kJ} \mathrm{~mol}^{-1}$. If a late (i.e. product-like) transition state is assumed, these relative energy values are in agreement with the yields obtained, in that the less polar diastereomer $\mathbf{6}$ is the major product and the more polar diastereomer $\mathbf{5}$ is the minor product.

A

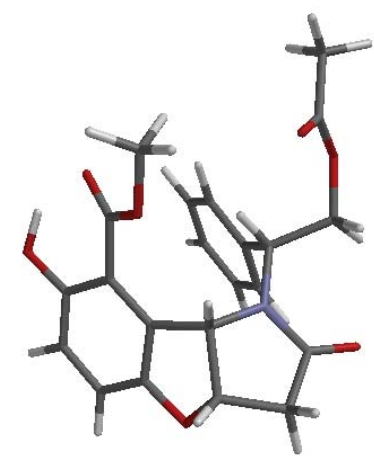

B

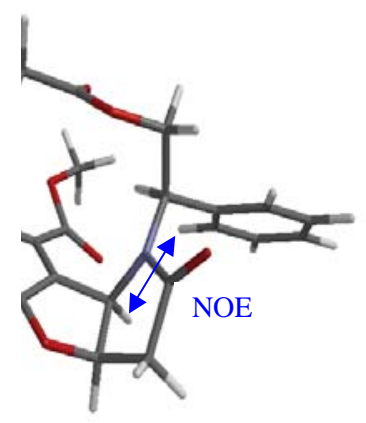

more polar diastereomer 5

$\mathrm{E}=92.295 \mathrm{~kJ} \mathrm{~mol}^{-1}$

less polar diastereomer 6 $\mathrm{E}=90.350 \mathrm{~kJ} \mathrm{~mol}^{-1}$

Figure 1. Molecular models of the diastereomers of pyrrolidinonobenzofurans 5 and $\mathbf{6}$; A: $3 \mathrm{a} S, 8 \mathrm{~b} S$ configuration; $\mathrm{B}: 3 \mathrm{a} R, 8 \mathrm{~b} R$ configuration. 
In summary, the addition of chiral non-racemic silyloxypyrrole $\mathbf{3}$ to benzoquinone $\mathbf{4}$ proved to be low yielding. Nevertheless, the work described herein provides the first example of an addition of this type providing novel chiral non-racemic pyrrolidinonobenzofuran adducts. Further efforts to improve this type of annulation will focus on the use of more electron deficient silyloxypyrroles in an attempt to overcome the undesired redox reactions that apparently intervened in the present work.

\section{Experimental Section}

General Procedures. Melting points were determined using a Kofler hot-stage apparatus and are uncorrected. Optical rotations were determined on a Perkin-Elmer 341 polarimeter. Infrared spectra were recorded with a Perkin-Elmer 1600 series Fourier-transform infrared spectrometer as thin films between sodium chloride plates. ${ }^{1} \mathrm{H}$ and ${ }^{13} \mathrm{C}$ n.m.r. spectra were recorded as indicated on either a Bruker AC200 spectrophotometer operating at $200 \mathrm{MHz}$ for ${ }^{1} \mathrm{H}$ nuclei and $50 \mathrm{MHz}$ for ${ }^{13} \mathrm{C}$ nuclei, a Bruker DRX300 spectrophotometer operating at $300 \mathrm{MHz}$ for ${ }^{1} \mathrm{H}$ nuclei and $75 \mathrm{MHz}$ for ${ }^{13} \mathrm{C}$ nuclei, or a Bruker DRX400 spectrophotometer operating at $400 \mathrm{MHz}$ for ${ }^{1} \mathrm{H}$ nuclei and $100 \mathrm{MHz}$ for ${ }^{13} \mathrm{C}$ nuclei. Both ${ }^{1} \mathrm{H}$ and ${ }^{13} \mathrm{C}$ n.m.r spectra were interpreted with the aid of COSY, HETCOR and DEPT 135 experiments and are reported in p.p.m. downfield from tetramethylsilane as standard. High-resolution mass spectra were recorded using a VG7070 spectrometer operating with an ionisation potential of $70 \mathrm{eV}$ at a nominal resolution of 5000 or 10000 as appropriate. Major fragments are assigned where possible and their intensities given as percentages of the base peak. Tetrahydrofuran was dried using sodium/benzophenone and distilled prior to use. Flash chromatography was performed using either Merck Kieselgel 60 or Riedel-de-Haën Kieselgel S silica gel (both 230-400 mesh) or Merck aluminium oxide (70-230 mesh) with the indicated solvents. Compounds were visualized under ultraviolet light or by staining with iodine vapour or vanillin in methanolic sulfuric acid.

(R)-1-(2-Hydroxy-1-phenylethyl)-1,5-dihydropyrrol-2-one (1). ( $R$ )-(-)-2-Phenylglycinol ${ }^{8}$ (1.30 g, $7.29 \mathrm{mmol})$ was dissolved in water $(30 \mathrm{~mL})$ and 2,5-dimethoxy-2,5-dihydrofuran $(0.88 \mathrm{~mL}$, $7.29 \mathrm{mmol}$ ) was added dropwise. After stirring for several minutes, concentrated hydrochloric acid $(0.90 \mathrm{~mL})$ was added slowly to afford an orange mixture. The mixture was stirred at room temperature for $3 \mathrm{~h}$. Solid sodium bicarbonate was added to neutralize the mixture which was then extracted with dichloromethane $(6 \times 30 \mathrm{~mL})$ and dried over anhydrous magnesium sulfate. The solvent was evaporated at reduced pressure to afford a red oil that was purified by flash chromatography using ethyl acetate containing triethylamine (3\%) as eluent to afford the title compound $\mathbf{1}^{10}(0.56 \mathrm{~g}, 56 \%)$ as a red oil, $[\alpha]_{\mathrm{D}}-29.8(\mathrm{c}=0.9,1 \mathrm{M} \mathrm{HCl})\left\{\right.$ lit. $\left.^{10}[\alpha]_{\mathrm{D}}-21\right\} ; \delta_{\mathrm{H}}(200$ MHz, $\left.\mathrm{CDCl}_{3}\right) 3.80$ (1H, ddd, J 1.7, 1.7, 20.6 Hz, H-5A), 4.02-4.14 (3H, m, H-2'A, H-2'B, H-5B), 4.40 (1H, s, OH), 5.21 (1H, dd, J 5.6, 7.5 Hz, H-1'), 6.13 (1H, ddd, J 1.7, 1.9, $6.0 \mathrm{~Hz}, \mathrm{H}-3$ ), 7.04 
(1H, ddd, $J$ 1.7, 1.7, $6.0 \mathrm{~Hz}, \mathrm{H}-4)$, 7.21-7.37 (5H, m, Ph). The NMR data were in agreement with the literature values. ${ }^{10}$

(R)-2-(2-Oxo-2,5-dihydropyrrol-1-yl)-2-phenylethyl acetate (2). To a solution of (R)-1-(2hydroxy-1-phenylethyl)-1,5-dihydropyrrol-2-one $1(0.47 \mathrm{~g}, 2.30 \mathrm{mmol})$ in dichloromethane (5 $\mathrm{mL})$ and triethylamine $(0.65 \mathrm{~mL}, 4.6 \mathrm{mmol})$ were added acetic anhydride $(0.33 \mathrm{~mL}, 3.50 \mathrm{mmol})$ and 4-(dimethylamino)pyridine $(4.0 \mathrm{mg})$ under nitrogen and the mixture was left stirring overnight. The solvent was evaporated at reduced pressure to give a dark red oil that was purified by flash chromatography using hexane-ethyl acetate (2:8) as eluent to afford the title compound $2(0.40 \mathrm{~g}, 70 \%)$ as a red oil, $[\alpha]_{\mathrm{D}}-78.3\left(\mathrm{c}=0.84, \mathrm{CH}_{2} \mathrm{Cl}_{2}\right)$, (Found: $\mathrm{M}^{+}, 245.1051, \mathrm{C}_{14} \mathrm{H}_{15} \mathrm{NO}_{3}$ requires 245.1052); $v_{\max }\left(\right.$ film) $/ \mathrm{cm}^{-1} 1740 \mathrm{~s}(\mathrm{OC}=\mathrm{O}), 1681 \mathrm{~s}(\mathrm{NC}=\mathrm{O}), 1239 \mathrm{~s} ; \delta_{\mathrm{H}}(200 \mathrm{MHz}$, $\left.\mathrm{CDCl}_{3}\right) 2.02$ (3H, s, OCOMe), 3.70 (1H, ddd, $J$ 1.8, 1.8, $20.0 \mathrm{~Hz}, \mathrm{H}-5$ 'A), 4.05 (1H, ddd, $J$ 1.8, 1.8, 20.0 Hz, H-5'B), 4.53 (1H, dd, J 5.2, 11.5 Hz, H-1A), 4.72 (1H, dd, J 8.9, 11.5 Hz, H-1B), 5.63 (1H, dd, J 5.2, 8.9 Hz, H-2), 6.17 (1H, ddd, J 1.8, 1.8, 6.0 Hz, H-3'), 7.10 (1H, ddd, J 1.8, 1.8, $6.0 \mathrm{~Hz}, \mathrm{H}-4$ '), 7.24-7.37 (5H, m, Ph); $\delta_{\mathrm{C}}\left(50 \mathrm{MHz}, \mathrm{CDCl}_{3}\right) 20.5\left(\mathrm{CH}_{3}, \mathrm{OCOMe}\right), 49.4\left(\mathrm{CH}_{2}\right.$, C-5'), 52.8 (CH, C-2), $62.6\left(\mathrm{CH}_{2}, \mathrm{C}-1\right), 127.1$ (CH, C-3'), $127.2(\mathrm{CH}, o-\mathrm{Ph}$ or m-Ph), $127.9(\mathrm{CH}$, p-Ph), 128.7 (CH, m-Ph or o-Ph), 136.3 (C, Ph), 143.4 (CH, C-4'), 170.4 (C, OCOMe), 171.4 (C, $\mathrm{C}-2$ '); $\mathrm{m} / \mathrm{z} 245$ (M+, 4\%), $185\left(\mathrm{M}-\mathrm{CH}_{3} \mathrm{CO}_{2} \mathrm{H}, 10\right), 172\left(\mathrm{M}-\mathrm{CH}_{3} \mathrm{CO}_{2} \mathrm{CH}_{2}, 100\right)$.

(R)-2-[2-(tert-Butyldimethylsilyloxy)pyrrol-1-yl]-2-phenylethyl acetate (3). To a solution of (R)-2-(2-oxo-2,5-dihydropyrrol-1-yl)-2-phenylethyl acetate $2(1.14 \mathrm{~g}, 4.65 \mathrm{mmol})$ in dichloromethane $(18 \mathrm{~mL})$ were added triethylamine $(1.30 \mathrm{~mL}, 9.30 \mathrm{mmol})$ and tertbutyldimethylsilyl trifluoromethanesulfonate $(1.18 \mathrm{~mL}, 4.65 \mathrm{mmol})$ under nitrogen at room temperature. The mixture was left to stir for $1 \mathrm{~h}$. The solvent was evaporated to give a dark brown residue which was then purified by flash chromatography on alumina using hexane-ethyl acetate (2:98) as eluent to afford the title compound $3(1.67 \mathrm{~g}, 69 \%)$ as a pale yellow oil, $[\alpha]_{\mathrm{D}}-$ 3.09 ( $\mathrm{c}=0.89, \mathrm{CH}_{2} \mathrm{Cl}_{2}$ ), (Found: $\mathrm{M}^{+}, 359.1914, \mathrm{C}_{20} \mathrm{H}_{29} \mathrm{NO}_{3} \mathrm{Si}$ requires 359.1917); $v_{\max }$ (film)/cm ${ }^{-1} 1744 \mathrm{~s}(\mathrm{OC}=\mathrm{O}), 1706 \mathrm{~m}$ (NCO), 1230s ( $\left.\mathrm{SiCH}_{3}\right), 1041 \mathrm{~m}(\mathrm{SiO}) ; \delta_{\mathrm{H}}\left(200 \mathrm{MHz}, \mathrm{CDCl}_{3}\right)$ 0.01 (3H, s, SiMeMe ${ }^{t} \mathrm{Bu}$ ), 0.17 (3H, s, SiMeMe $\left.{ }^{t} \mathrm{Bu}\right), 0.87$ (9H, s, $\mathrm{SiMe}_{2}{ }^{\mathrm{t}} \mathrm{Bu}$ ), 1.99 (3H, s, OCOMe), 4.59 (2H, m, H-1), 5.22 (1H, dd, J 1.8, 3.6 Hz, H-3'), 5.50 (1H, dd, J 6.5, 7.4 Hz, H2), 5.97 (1H, t, $J$ 3.6 Hz, H-4'), 6.34 (1H, dd, J 1.8, 3.6 Hz, H-5'), 7.06-8.02 (5H, m, Ph); $\delta_{\mathrm{C}}(75$ $\left.\mathrm{MHz}, \mathrm{CDCl}_{3}\right)-5.2\left(\mathrm{CH}_{3}, \mathrm{SiMeMe}{ }^{\mathrm{t}} \mathrm{Bu}\right),-4.9\left(\mathrm{CH}_{3}, \mathrm{SiMeMe}{ }^{\mathrm{t}} \mathrm{Bu}\right), 17.9\left(\mathrm{C}, \mathrm{SiMe}_{2}{ }^{\mathrm{B}} \mathrm{Bu}\right), 20.8\left(\mathrm{CH}_{3}\right.$, OCOMe), $25.5\left(\mathrm{CH}_{3}, \mathrm{SiMe}_{2}{ }^{\mathrm{B}} \mathrm{Bu}\right), 55.9(\mathrm{CH}, \mathrm{C}-2), 65.2\left(\mathrm{CH}_{2}, \mathrm{C}-1\right), 87.6(\mathrm{CH}, \mathrm{C}-3), 105.6(\mathrm{CH}$, C-4'), 109.6 (CH, C-5'), 126.7 (CH, o-Ph or m-Ph), 127.7 (CH, p-Ph), 128.6 (CH, m-Ph or o-Ph), 135.5 (C, Ph), 142.4 (C, C-2), 170.7 (C, OCOMe); m/z 359 (M+, 44\%), 344 (M-CH3, 1), 300 (M$\left.\mathrm{CH}_{3} \mathrm{CO}_{2}, 2\right), 286\left(\mathrm{M}-\mathrm{CH}_{3} \mathrm{CO}_{2} \mathrm{CH}_{2}, 2\right), 244\left(\mathrm{M}-\mathrm{SiMe}_{2}{ }^{\mathrm{t}} \mathrm{Bu}, 3\right), 228\left(\mathrm{M}-\mathrm{OSiMe}{ }_{2}{ }^{\mathrm{B}} \mathrm{Bu}, 1\right), 43$ $\left(\mathrm{CH}_{3} \mathrm{CO}, 100\right)$.

2-Carbomethoxy-1,4-benzoquinone (4). A mixture of methyl 2,5-dihydroxybenzoate (1.0 g, $6.0 \mathrm{mmol})$ and anhydrous sodium sulfate $(1.5 \mathrm{~g})$ in dry toluene $(50.0 \mathrm{~mL})$ was stirred with manganese dioxide $(5.2 \mathrm{~g}, 60.0 \mathrm{mmol})$ for $2 \mathrm{~h}$. The suspension was filtered through sodium sulfate and Celite and the filter cake was washed with toluene. The solvent was removed under reduced pressure to afford the title compound $4(0.45 \mathrm{~g}, 46 \%)$ as an orange oil; $\delta_{\mathrm{H}}(200 \mathrm{MHz}$, 
$\left.\mathrm{CDCl}_{3}\right) 3.92$ (3H, s, OMe), 6.83 (2H, d, J $\left.1.2 \mathrm{~Hz}, \mathrm{H}-5, \mathrm{H}-6\right), 7.12$ (1H, t, J $\left.1.2 \mathrm{~Hz}, \mathrm{H}-3\right)$. The ${ }^{1} \mathrm{H}$ n.m.r. data were in agreement with the literature values. ${ }^{11}$

Methyl (3aS, 8bS, 1'R)-1-(2-acetoxy-1-phenylethyl)-7-hydroxy-2-oxo-2,3,3a,8b-tetrahydro$1 H$-[1]benzofuro[3,2-b]pyrrole-8-carboxylate 5 and (3aR, 8bR, 1'R)-1-(2-acetoxy-1phenylethyl)-7-hydroxy-2-oxo-2,3,3a,8b-tetrahydro-1H-[1]benzofuro[3,2-b]pyrrole-8-

carboxylate (6). To a solution of 2-carbomethoxy-1,4-benzoquinone 4 (0.1 g, $0.60 \mathrm{mmol})$ in acetonitrile $(4 \mathrm{~mL})$ was added a solution of silyloxypyrrole $3(0.238 \mathrm{~g}, 0.60 \mathrm{mmol})$ in acetonitrile (3 mL) under nitrogen. The reaction mixture was stirred at room temperature overnight. Pyridinium $p$-toluenesulfonate (18 mg, $0.07 \mathrm{mmol}$ ) was added and the colour changed from blue to purple-brown. The reaction mixture was stirred for another night and the solvent evaporated under reduced pressure to afford a red-brown crude oil. Purification by flash chromatography using hexane-ethyl acetate (gradient elution 7:3 to 4:6) followed by PLC on silica using hexaneethyl acetate (1:1) afforded methyl ( $3 \mathrm{a} S$, 8bS, 1'R)-1-(2-acetoxy-1-phenyethyl)-7-hydroxy-2-oxo2,3,3a,8b-tetrahydro-1H-[1]benzofuro[3,2,b]pyrrole-8-carboxylate 5 (7.6 mg, 3\%) and methyl (3aR, $\quad 8 \mathrm{~b} R, \quad 1 ' R)-1-(2-a c e t o x y-1-p h e n y e t h y l)-7-h y d r o x y-2-o x o-2,3,3 \mathrm{a}, 8 \mathrm{~b}-t e t r a h y d r o-1 H$ [1]benzofuro[3,2,b]pyrrole-8-carboxylate 6 (29.1 mg, $12 \%)$.

Diastereomer 5, pale yellow oil, $[\alpha]_{\mathrm{D}}-32.08$ (c = 0.48, $\mathrm{CH}_{2} \mathrm{Cl}_{2}$ ), (Found: $\mathrm{M}^{+}, 411.1316$, $\mathrm{C}_{22} \mathrm{H}_{21} \mathrm{NO}_{7}$ requires 411.1318); $v_{\max }(\mathrm{film}) / \mathrm{cm}^{-1} 3420 \mathrm{v}(\mathrm{OH}), 2926 \mathrm{~m}, 1738 \mathrm{~m}(\mathrm{C}=\mathrm{O}), 1697 \mathrm{~m}$ $(\mathrm{C}=\mathrm{O}), 1265 \mathrm{~s}(\mathrm{C}-\mathrm{O}) ; \delta_{\mathrm{H}}\left(200 \mathrm{MHz}, \mathrm{CDCl}_{3}\right) 2.10$ (3H, s, OCOMe), 2.90 (2H, m, H-3), 3.98 (3H, s, OMe), 4.63 (1H, dd, J 6.3, 11.0 Hz, H-2'B), 4.76 (1H, dd, J 6.3, 8.0 Hz, H-1'), 5.01 (1H, dd, $J$ 8.0, 11.0 Hz, H-2'A), 5.16 (1H, m, H-3a), 5.62 (1H, d, J $5.1 \mathrm{~Hz}, \mathrm{H}-8 \mathrm{~b}), 6.79$ (1H, d, J 8.9 Hz, H6), 6.93 (1H, d, J 8.9 Hz, H-5), 7.22-7.35 (5H, m, Ph), $10.27(1 \mathrm{H}, \mathrm{s}, \mathrm{OH}) ; \delta_{\mathrm{C}}\left(100 \mathrm{MHz}, \mathrm{CDCl}_{3}\right)$ $21.0\left(\mathrm{CH}_{3}, \mathrm{OCOMe}\right), 37.4\left(\mathrm{CH}_{2}, \mathrm{C}-3\right), 52.5\left(\mathrm{CH}_{3}, \mathrm{CO}_{2} \mathrm{Me}\right), 57.1\left(\mathrm{CH}, \mathrm{C}-1^{\prime}\right), 63.8\left(\mathrm{CH}_{2}, \mathrm{C}-2^{\prime}\right)$, 67.3 (CH, C-8b), 81.5 (CH, C-3a), 109.4 (C, C-8), 118.4 (CH, C-6), 120.5 (CH, C-5), 123.4 (C, C-8a), 126.5 (CH, o-Ph or m-Ph), 127.5 (CH, p-Ph), $128.3(\mathrm{CH}, m-\mathrm{Ph}$ or o-Ph), $136.8(\mathrm{C}, \mathrm{Ph})$, 154.2 (C, C-4a), 156.6 (C, C-7), 169.5 (C, $\mathrm{CO}_{2} \mathrm{Me}$ ), 170.7 (C, OCOMe), 172.8 (C, C-2); m/z 411 $\left(\mathrm{M}^{+}, 35 \%\right), 351\left(\mathrm{M}-\mathrm{HOCOCH}_{3}, 4 \%\right), 338\left(\mathrm{M}-\mathrm{CH}_{2} \mathrm{OCOCH}_{3}, 24 \%\right), 249\left(\mathrm{M}-\mathrm{CHPhCH}_{2} \mathrm{OCOCH}_{3}\right.$, 25\%), 159 (65\%), 106 (100\%), 43 ( $\left.\mathrm{CH}_{3} \mathrm{CO}, 49 \%\right)$.

Diastereomer 6, pale red oil, $[\alpha]_{\mathrm{D}}+62.26\left(\mathrm{c}=1.06, \mathrm{CH}_{2} \mathrm{Cl}_{2}\right)$, (Found: $\mathrm{M}^{+}, 411.1319, \mathrm{C}_{22} \mathrm{H}_{21} \mathrm{NO}_{7}$ requires 411.1318); $v_{\max }($ film $) / \mathrm{cm}^{-1} 3241 \mathrm{v}(\mathrm{OH}), 2926 \mathrm{~m}, 1737 \mathrm{~m}(\mathrm{C}=\mathrm{O}), 1682 \mathrm{~m}(\mathrm{C}=\mathrm{O}), 1265 \mathrm{~s}$ (C-O); $\delta_{\mathrm{H}}\left(400 \mathrm{MHz}, \mathrm{CDCl}_{3}\right) 1.70$ (3H, s, OCOMe), 2.90 (2H, m, H-3), 3.49 (3H, s, CO $2 \mathrm{Me}$ ), 4.48 (1H, dd, J 4.9, 10.9 Hz, H-2'B), 4.70 (1H, broad, H-1'), 5.00 (1H, t, J 10.9 Hz, H-2'A), 5.19 $(1 \mathrm{H}, \mathrm{t}, J 5.0 \mathrm{~Hz}, \mathrm{H}-3 \mathrm{a}), 5.52$ (1H, d, $J 5.0 \mathrm{~Hz}, \mathrm{H}-8 \mathrm{~b}), 6.96$ (1H, d, $J 8.9 \mathrm{~Hz}, \mathrm{H}-6), 7.05$ (1H, d, $J$ $8.9 \mathrm{~Hz}, \mathrm{H}-5), 7.24-7.31$ (5H, m, Ph), $10.44(1 \mathrm{H}, \mathrm{s}, \mathrm{OH}) ; \delta_{\mathrm{C}}\left(100 \mathrm{MHz}, \mathrm{CDCl}_{3}\right) 20.5\left(\mathrm{CH}_{3}\right.$, OCOMe), $37.1\left(\mathrm{CH}_{2}, \mathrm{C}-3\right), 52.3\left(\mathrm{CH}_{3}, \mathrm{CO}_{2} \mathrm{Me}\right), 56.2\left(\mathrm{CH}, \mathrm{C}-1\right.$ '), $62.8\left(\mathrm{CH}_{2}, \mathrm{C}-2\right)$, $66.1(\mathrm{CH}, \mathrm{C}-$ 8b), 81.8 (CH, C-3a), 109.8 (C, C-8), 118.2 (CH, C-6), 120.4 (CH, C-5), 123.9 (C, C-8a), 126.5 (CH, o-Ph or $m-\mathrm{Ph}), 127.8(\mathrm{CH}, p-\mathrm{Ph}), 128.7(\mathrm{CH}, m-\mathrm{Ph}$ or $o-\mathrm{Ph}), 136.2(\mathrm{C}, \mathrm{Ph}), 154.4(\mathrm{C}, \mathrm{C}-$ 4a), 156.8 (C, C-7), 169.3 (C, $\mathrm{CO}_{2} \mathrm{Me}$ ), 170.5 (C, OCOMe), 173.2 (C, C-2); m/z 411 (M , 32\%), $351\left(\mathrm{M}-\mathrm{HOCOCH}_{3}, 7 \%\right), 338\left(\mathrm{M}-\mathrm{CH}_{2} \mathrm{OCOCH}_{3}, 18 \%\right), 249\left(\mathrm{M}-\mathrm{CHPhCH}_{2} \mathrm{OCOCH}_{3}, 14 \%\right), 159$ (100\%), $43\left(\mathrm{CH}_{3} \mathrm{CO}, 60 \%\right)$. 


\section{References}

1. Brimble, M. A. Pure Appl. Chem. 2000, 72, 1635.

2. $\quad$ Brimble, M. A.; Duncalf, L. J.; Nairn, M. R. Nat. Prod. Rev. 1999, 16, 267.

3. Bausanne, I.; Royer, J. Tetrahedron Lett. 1996, 37, 1213.

4. Dudot, B.; Micouin, L.; Bausanne, I.; Royer, J. Synthesis 1999, 4, 688.

5. Bausanne, I.; Schwardt, O.; Royer, J.; Pichon, M.; Figadère, B.; Cavé, A. Tetrahedron Lett. 1997, 38, 2259.

6. Dudot, B.; Royer, J.; Sevrin, M.; George, P. Tetrahedron Lett. 2000, 41, 4367.

7. Zanardi, F.; Battistini, G.; Rassu, G.; Pinna, L.; Mor, M.; Culeddu, N.; Casiraghi, G. J. Org. Chem. 1998, 63, 1368.

8. Giannis, A.; Sandhoff, K. Angew. Chem., Int. Ed. 1998, 28, 218.

9. Abiko, A.; Masamune, S. Tetrahedron Lett. 1992, 33, 5517.

10. Bausanne, I.; Travers, C.; Royer, J. Tetrahedron: Asymmetry 1998, 9, 797.

11. Schleusener, E.; Eugster, C. H. Helv. Chim. Acta 1972, 55, 986. 